AsCLEPIO. Revista de Historia de la Medicina y de la Ciencia

67 (1), enero-junio 2015, p077

ISSN-L:0210-4466

http://dx.doi.org/10.3989/asclepio.2015.03

DOSSIER: CIENCIA Y SABERES AGRÍCOLAS EN CONSTRUCCIÓN EN LA HISTORIA DE AMÉRICA LATINA Y EL CARIBE:

AGENTES, REDES Y CÍRCUITOS (SIGLOS XVIII-XX) / AGRICULTURAL SCIENCE AND KNOWLEDGE IN CONSTRUCTION IN

THE HISTORY OF LATIN AMERICA AND THE CARIBBEAN: NETWORKS, ACTORS AND CIRCUITS (XVIII-XX CENTURIES)

\title{
EL ORIGEN AFRICANO DEL CULTIVO DEL ARROZ EN LAS AMÉRICAS
}

\author{
Judith A. Carney \\ Department of Geography, UCLA \\ carney@geog.ucla.edu \\ Traducido por Natalia Santamaría Laorden
}

Recibido: 5 noviembre 2014. Aceptado: 1 febrero 2015.

Cómo citar este artículo/Citation: Carney, Judith A. (2015), "El origen africano del cultivo del arroz en Las Américas", Asclepio 67 (1): p077. doi: http://dx.doi.org/10.3989/asclepio.2015.03

RESUMEN: El arroz no empezó a ser cultivado en las Américas sino hasta el periodo del comercio transatlántico de esclavos. Para el siglo XVIII este cultivo ya se había establecido extensamente en plantaciones desde Carolina del Sur hasta Brasil. Cultivado por esclavos así como cimarrones, tanto para la subsistencia como para la exportación, el comienzo de la cultivación de arroz en las Américas invariablemente se ha atribuido a los dueños de plantaciones europeos. Este artículo presenta evidencia del importante papel que desempeñaron los africanos en establecer la cultura del arroz en el Nuevo Mundo. Este trabajo se enfoca sobre el arroz africano (Oryza glaberrima), personas esclavizadas de África occidental para quienes este cultivo era un alimento básico, y un sistema de conocimiento indígena sobre el arroz con características idénticas entre el Atlántico africano y americano. Un estudio comparativo de usos del suelo, métodos de cultivo, procesos de molienda y tradiciones culinarias ilumina el tema de la difusión de la cultura africana de arroz a las Américas, así como la labor que desempeñaron los esclavos de África occidental en liderar el cultivo de arroz para eventualmente convertirlo en un alimento básico de subsistencia en el Nuevo Mundo.

PALABRAS CLAVE: Arroz africano; Diáspora africana; Comercio transatlántico de esclavos; Sistema de conocimiento tradicional; Subsistencia.

\section{THE AFRICAN ORIGINS OF RICE CULTIVATION IN THE AMERICAS}

ABSTRACT: Until the period of the transatlantic slave trade, rice was not cultivated in the Americas. By the eighteenth century the crop was widely established across plantation societies from South Carolina to Brazil. Grown by slaves as well as maroons, for subsistence and also for export, the onset of rice cultivation in the Americas has long been attributed to European planters. This article presents evidence that supports African agency in establishing rice culture in the New World. Emphasis is on African rice (Oryza glaberrima), enslaved West Africans for whom the crop was a dietary staple, and an indigenous rice knowledge system with identical features across the African and American Atlantic. A comparative analysis of land use, methods of cultivation, milling and cooking traditions illuminates the diffusion of African rice culture to the Americas and the role of West African slaves in pioneering rice as a New World subsistence staple.

KEY WORDS: African rice; African diaspora; Transatlantic slave trade; Indigenous knowledge system; Subsistence.

Copyright: () 2015 CSIC. Este es un artículo de acceso abierto distribuido bajo los términos de la licencia Creative Commons Attribution-Non Commercial (by-nc) Spain 3.0. 
Wade in the water, Wade in the water, children

Wade in the water, God is going to trouble the water.

See that band all dressed in red,

God is going to trouble the water.

It looks like the band that Moses led.

God is going to trouble the water.

El canto religioso afroamericano "Anda por el agua" recuerda el pasaje a la libertad que la división del Mar Rojo proporcionó a los israelitas esclavizados. También sirve como metáfora significativa para examinar el cultivo de arroz y sus orígenes en las Américas. A diferencia de en la canción, los niños de África fueron conducidos a través de las aguas turbulentas de la esclavitud africana al cautiverio. Los esclavos de África Occidental trajeron con ellos un conocimiento del sistema indígena que establecería el arroz como el cultivo de subsistencia en una amplia región, desde Carolina del Sur a los trópicos de Sudamérica. El arroz es el único cereal que exige abundantes cantidades de agua. Quienes lo cultivan andan a través de humedales para su cosecha. El agua es, además, esencial para preparar el cereal para su consumición. El arroz llegó a las Américas en barcos de esclavos, que hacían la travesía transatlántica, como provisiones para sus supervivientes. El cultivo, el procesamiento y la preparación del arroz representan una forma de conocimiento significativa establecida por los esclavos en las Américas. La importancia del arroz en la cocina de la diáspora africana pervive incluso hoy en día en las recetas de la memoria y la identidad cultural a través del Atlántico Negro.

La diáspora africana se extendió a las plantas y a las personas. El arroz llevó a la difusión de las plantas africanas y a sistemas agrícolas que dieron forma al ambiente, las preferencias en las comidas, economías, resistencia e identidad cultural en la era de la esclavitud en las plantaciones. Durante el siglo dieciocho, al arroz producido por la mano de los esclavos convirtió a Carolina del Sur en la economía de plantación más rica de Norte América. La base de esta poderosa economía se hallaba en los esclavos del África Occidental, que estaban calificados para el cultivo del arroz en medio ambientes agrícolas de diversa naturaleza. Al arrojar luz sobre los orígenes africanos del arroz de Carolina en las primeras décadas del asentamiento de la colonia en 1670, este ensayo propone un análisis político-ecológico de la historia del arroz en las Américas. El ensayo enlaza la transformación del paisaje regional con los sistemas de conocimiento indígena, las relaciones de poder, las luchas sobre el proceso de trabajo, la resistencia y la negociación. Mientras que los propietarios de las plantaciones de Carolina se apropiaron del conocimiento del cultivo y el proceso del arroz de aquellos familiarizados con él, la mano experta de los esclavos les proporcionó la posibilidad de negociar un proceso de trabajo sustancialmente diferente al que era propio en las plantaciones de los esclavos. La emergencia de un sistema de labores en el trabajo en el sur de Carolina ofrece evidencia indirecta de la agencia africana en el establecimiento del arroz en la región occidental del Atlántico.

\section{DE ARROCES Y ESCLAVOS}

La mayoría de los americanos desconocen que el sistema de plantación más lucrativo en Norteamérica no estaba basado en los cultivos tradicionalmente asociados con la esclavitud (el algodón y el azúcar) sino con el arroz, del que hubo una demanda extraordinaria en la Europa del siglo dieciocho. El cereal se usaba para fermentar cerveza, hacer papel y se convirtió en condimento apreciado por la clase media de la Europa católica para acompañar el pescado los viernes de vigilia y durante Cuaresma. Los esclavos familiarizados con el cultivo del arroz en África Occidental acompañaron a los primeros propietarios de las plantaciones que Ilegaron a Carolina del Sur en 1670. La cosecha del arroz estaba bien establecida en la colonia para la década de 1690 y la transición del cereal a cultivo de plantación se completó a comienzos del siglo dieciocho.

Fue, precisamente, el sistema de plantación de arroz lo que creó la riqueza para permitir que Carolina del Sur, antes de la guerra civil, liderara la secesión de la Confederación de la Unión. Antes de la guerra civil, se cultivaba el arroz en el espacio de cuarenta millas de la costa Atlántica, a lo largo de humedales de dieciséis ríos, desde la frontera entre el Norte y el Sur de Carolina al río de St. Mary, que separaba Florida de Georgia (figura 1). En las vísperas de la Guerra Civil, casi 100,000 esclavos estaban cultivando 70,000 acres de pantanos, en 500 plantaciones de arroz.

Hasta la década de los 70, la historiografía de la economía del arroz en Estados Unidos atribuía, de forma rutinaria, los orígenes del cereal a la agencia de los propietarios de las plantaciones. Los documentos de la historia sobre el arroz de Carolina encomiaban a los primeros propietarios por descubrir cómo cultivar una planta tropical que no se cultivaba en sus propios países y por desarrollar un sistema de cultivo ingenioso 
tan apropiado a los pantanos de Carolina (Doar, 1970 (1936); Heyward, 1937; Salley, 1919, pp. 3-23). Esta visión fue seriamente cuestionada en 1974, con la publicación del libro Black Majority del historiador Peter Wood. Wood sostenía que los plantadores de Carolina, de origen inglés y francés hugonote, no tenían experiencia previa cultivando arroz. Era muy poco probable que ellos, de manera independiente, hubieran desarrollado las técnicas sofisticadas necesarias para cultivar un cereal en el agua. Al final del siglo diecisiete, cuando el Sur de Carolina se convirtió en una colonia, no estaba disponible un conocimiento detallado de los sistemas asiáticos de cultivo. Los únicos habitantes de la colonia que tenían experiencia en el cultivo del arroz eran los esclavos originarios de la zona de cultivo del arroz de África Occidental en la costa norte de Guinea. Fue en los esclavos de Carolina, mantuvo Wood, donde hay que encontrar los orígenes del arroz ya que ellos sólo poseían el conocimiento necesario, la experiencia y las habilidades necesarias para el cultivo del cereal. Wood se enfrentó a la escasez de crónicas históricas en el periodo colonial temprano en general y a los orígenes del arroz, de manera específica. Aunque pudo documentar referencias a esclavos cultivando arroz como comida básica en sus parcelas de subsistencia durante el periodo colonial temprano, la crónica escrita no atribuye a los esclavos un papel de tutor en el establecimiento del arroz. Por supuesto, hay que considerar que la esclavitud como sistema no reconocía la contribución de sus víctimas.

Figura 1

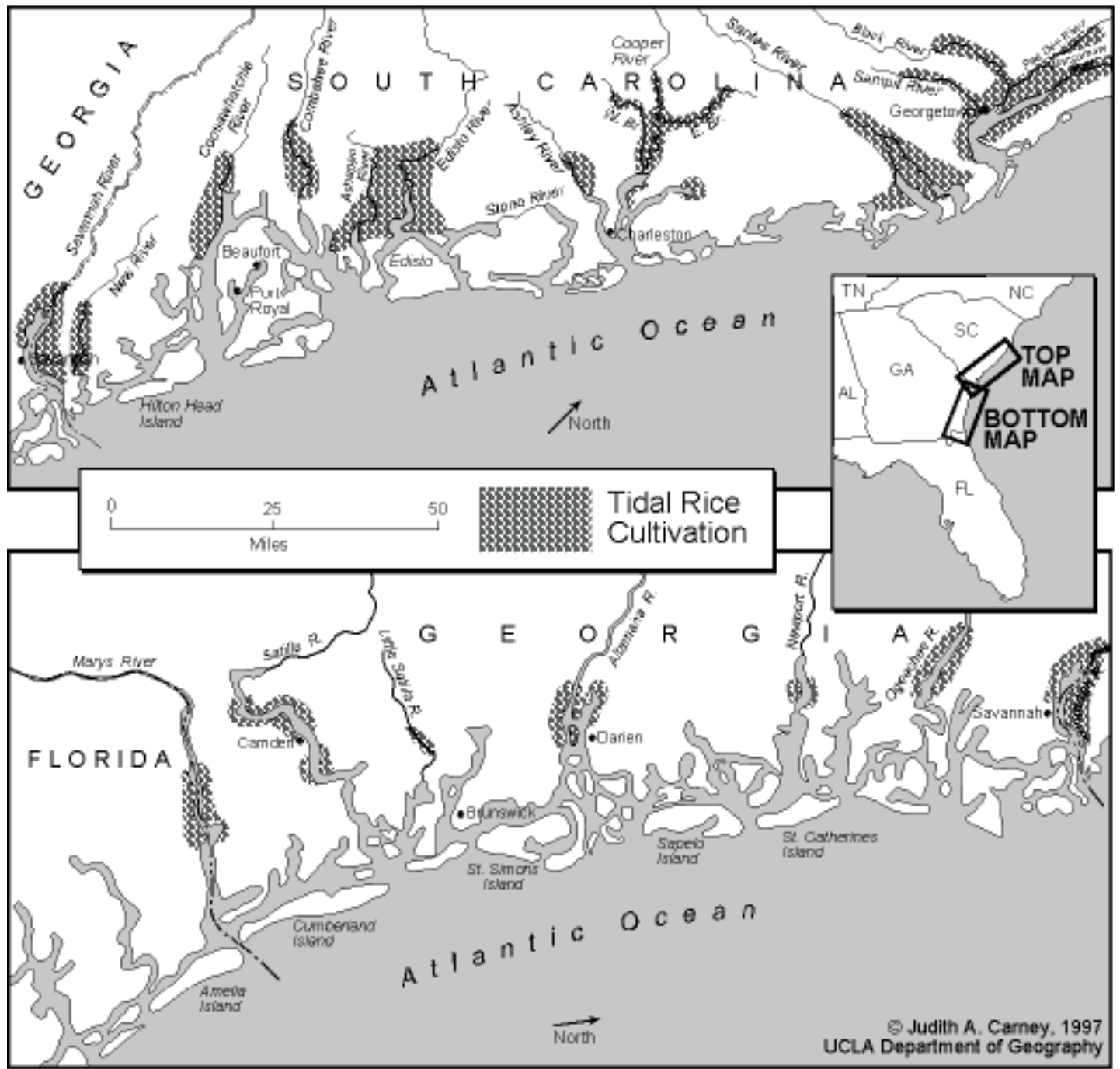


A pesar de que las investigaciones de Wood (1974) resultaran en una visión renovada sobre el papel africano en dar forma a los humedales plantados con arroz, todavía persistían dudas sobre si los propietarios de las plantaciones recluyeron a esclavos de la región de arroz del África Occidental para ayudarles a desarrollar una plantación que los propietarios eran capaces de reconocer por si solos, o si los esclavos nacidos en África iniciaron el cultivo del arroz en el Sur de Carolina a través de sus esfuerzos por desarrollar un cultivo para su propia subsistencia. Un enfoque político-ecológico que analice paisajes agrícolas y relaciones de poder permite acercarse a esta compleja cuestión. Implica reconsiderar la manera en la que los historiadores han visto el arroz. En lugar de considerar el cereal como una mercancía a ser consumida y vendida, se examina el arroz como un sistema de conocimiento indígena cuya expresión en diferentes medio ambientes fue mediada a través de relaciones de poder en el espacio geográfico. Cambiar el aparato analítico desde el que concebir el arroz, de una mercancía a un sistema de conocimiento, arroja luz sobre el uso de la tierra y el cultivo del cereal durante la época de la esclavitud transatlántica, a la vez que facilita la recuperación de los orígenes culturales de su cultivo en Carolina del Sur.

La argumentación de este ensayo está apoyada en tres formas de investigación: un trabajo de campo en los sistemas de arroz de África Occidental, una revisión de materiales históricos y de archivo relacionados con la historia del arroz y un examen interdisciplinario en botánica, arqueología y lingüística histórica sobre la antigüedad del arroz africano. El campo de trabajo en los principios de tratamiento del suelo y el agua de los sistemas de arroz africanos revela las consideraciones sociales y ecológicas que han dado forma a la cultura del arroz en la región por un largo periodo ${ }^{1}$. Los materiales históricos y de archivo establecen la presencia de la cultura del arroz, en un tiempo anterior a los viajes marítimos europeos, así como la presencia de los medios ambientes agrícolas plantados en el Sur de Carolina en el periodo colonial temprano. Una comparación entre los sistemas de arroz del Atlántico africano y americano revela la importancia de las relaciones de poder para dar forma a la difusión del cereal, el modelo de la cultura del arroz en la colonia de Carolina y el proceso de trabajo de la plantación.

\section{CRÓNICAS HISTÓRICAS DE LOS SISTEMAS DE ARROZ EN EL ATLÁNTICO AFRICANO}

Aunque el arroz se cultiva en unos 20 microambientes diferentes en África Occidental, un estudio en el tipo de agua que influye el cultivo revela tres amplios medios agrícolas: el que depende de la lluvia, el pantano en tierra adentro y el terreno inundable por las mareas. El sistema dependiente de la lluvia se refiere al arroz que se cultiva únicamente con las precipitaciones, generalmente en áreas en la que las lluvias exceden los 1000 milímetros por año. La simiente del arroz se planta directamente en la tierra. El pastoreo del ganado forma una secuencia importante rotacional en este sistema dependiente de la lluvia; una vez que se ha cosechado el cultivo, el ganado pasta el rastrojo, consiguiendo fertilizar el suelo con su movimiento. El sistema del pantano en tierra adentro se refiere al cultivo del arroz en áreas que reciben agua complementaria, de un plantado de arroz en otro pantano o de medio ambientes que se benefician de reservas de agua como corrientes subterráneas. Las parcelas de terreno pueden ser sembradas directamente o trasplantadas. El tercer sistema, el terreno inundable, recibe agua de las mareas mientras que el depósito aluvial anual aumente. En los ríos de agua dulce, el terreno inundable se siembra directamente; sin embargo, los terrenos cerca de la costa pueden ser trasplantados en el caso de que la salinidad cree un problema. En muchas áreas del África Occidental, estos tres sistemas de cultivo de arroz tienen lugar en un terreno de pendiente que accede a diferentes fuentes de agua. Plantar arroz de esta forma reduce el riesgo de subsistencia a la vez que diversifica el problema del estancamiento en el trabajo que resultaría si sólo se emplease un sistema de producción.

Las crónicas históricas dan cuenta de la antigüedad de estos sistemas en África Occidental al mismo tiempo que revelan los aspectos sociales y ecológicos duraderos del cultivo de arroz africano. Para 1460, los portugueses habían completado la exploración de la Costa Norte de Guinea, la región densamente poblada de Senegal a Liberia que serviría como foco del comercio de esclavos. Durante los próximos siglos, los marineros llamarían a esta región la Costa de los Cereales o la Costa del Arroz, después de que se especializara en la producción de cereales, como mijo, sorgo y arroz. Siguiendo el paso de los portugueses, otras naciones europeas también dependieron del excedente de producción de cereales africanos para reabastecer provisiones. Para aquellos barcos que viajaban a lo largo de la costa africana occidental, el canal al sur del río Se- 
negal les llevaba a una región abundante en cereales. En el este de Liberia, el cultivo de cereales se convirtió gradualmente en el cultivo de raíces como ñames. Bajos en proteína y propicios a perecer en viajes largos, este tipo de cultivos resultaron menos significativos como alimentos de primera necesidad que los cereales. Aunque las referencias a la costa norte de Guinea evocan imágenes del comercio de esclavos atlántico, el término "Costa de los Cereales o Costa del Arroz" no lo hace. Y, sin embargo, los sistemas de agricultura occidentales africanos produjeron excedentes de cereal que alimentaron las densas poblaciones desde el Senegal hasta Liberia que los europeos esclavizaron después. Estos excedentes, abastecieron a los barcos de esclavos que iban a las Américas a través del Atlántico.

Las carabelas portuguesas que viajaban al sur del río de Senegal comenzaron las narrativas (los comentarios) sobre el arroz que también atrajeron la atención de marineros europeos. En 1446, décadas antes de que los barcos Ilegaran a la India, Stevam Alfonso llegó a la desembocadura de un gran río-probablemente, el Gambia-donde encontró el cultivo del arroz en pantanos de tierras bajas: "Se encontraron con un río de anchura y entraron en él con las carabelas... encontraron mucha de la tierra sembrada y muchos campos sembrados de arroz" (Eanes de Azurara, 1899, pp. 263-264). Alvise da Cadamosto, que llegó al río de Gambia en 1455 y en 1456, se dio cuenta de la importancia del cereal en la dieta de la región (Crone, 1937, p. 70). Los comentarios portugueses durante el resto de siglo quince mencionan compras de arroz y el posterior cultivo del arroz en el asentamiento de las islas de Cabo Verde, unas 500 millas más allá de la costa de Senegal (Carreira, 1984, pp. 27-28; Brooks, 1993, pp. 276-296; Barry, 1998, pp. 79, 107-108, 117-118).

Las islas de Cabo Verde emergieron como un centro comercial fundamental para la expansión transatlántica del comercio portugués. Los barcos en viajes transatlánticos salían hacia allá en el otoño y el invierno con los vientos dominantes del noreste y siguieron hacia el sur por la corriente canaria, antes de continuar a Brasil, África Occidental o la India. Para el comienzo del siglo dieciséis, el cultivo del arroz ya se había desarrollado en Santiago, la isla de los archipiélagos más apta para la agricultura, así como otras plantas africanas como el sorgo, el mijo y los ñames (Ribeiro, 1962, pp. 143-147; Duncan, 1972, p. 168; Blake, 1977, pp. 91-92; Carreira, 1984, pp. 47-62). Los alimentos de primera necesidad africanos aseguraron la subsistencia a los esclavos que las cultivaron y se convirtieron en excedentes para los barcos portugueses. El arroz apareció en las listas de alimentos de los barcos que se dirigían a la América portuguesa en 1514, mientras que una crónica de 1530 da cuenta de la exportación deliberada de la semilla de arroz de Santiago a Brasil (Brooks 1993, p. 149). Las referencias a las compras de arroz aumentan en las últimas décadas del siglo decimoséptimo con la llegada de barcos de otras naciones europeas de la Costa Norte Guineana y el aumento del comercio de esclavos transatlántico (Davies, 1970; Rodney, 1970, p. 21; Blake, 1977, pp. 91-92; Curtin, 1975, pp. 100-111; Brooks, 1993, p. 260).

Por su proximidad a las rutas de navegación, los primeros sistemas africanos de arroz mencionados en crónicas portuguesas fueron los procedentes de las mareas localizados a lo largo de los humedales del río de la costa norte de Guinea (Fernandes, 1951, p. 47; Jobson, (1623) 1904, p. 59). Un sistema de cultivo de marea en particular, practicado cerca de los estuarios costeros de Gambia, Guinea-Bissau y Guinea, recibió especial atención. Se le conoció como "arroz mangle", basado en el nombre de la vegetación que se limpió para permitir el cultivo agrícola en la zona. Este fue el más productivo de todos los sistemas de arroz africanos - su única desventaja fue la entrada potencial de agua marina, que depositaba una capa no deseada de sal en el campo cultivado. Para limitar esa posibilidad, los granjeros del arroz mangle diseñaron un sistema elaborado de manejo del agua. Cercaron el pantano de arroz mangle con diques para impedir que llegara el agua de las mareas marinas. La construcción de canales, compuertas y presas permitieron el manejo del agua mientras que la lluvia se usaba para desalinizar la tierra. Esta sofisticada transformación del paisaje produjo cometarios europeos considerables, incluso cuando ciclos de precipitación escasa resultasen en una tierra demasiado salina para el cultivo y el abandono temporal de los arrozales (Gomes, 1959 (1456), pp. 42-46).

Los ciclos de precipitación también influyeron si los arrozales se sembrarían directamente como era costumbre o se trasplantarían. En los años en los que se retrasó el comienzo del ciclo de lluvias, la siembra de semillas se estableció primero en pantanos internos para comenzar su crecimiento antes de ser replantados en el perímetro del mangle, una vez que comenzaran las lluvias. En 1594, más que un siglo antes de que un sistema similar diera forma a la economía de plantación de arroz del Sur de Carolina, el comerciante luso africano André Alvares de Almada escribió que los granjeros del arroz mangle "estaban cultivando sus cosechas en los depósitos del río y con un sistema de diques habían usado las mareas para su propia venta- 
ja" (Rodney, 1970, pp. 20-21). La descripción de Almada y los comentarios de otros observadores europeos no deja lugar a duda sobre las habilidades del África Occidental para cultivar arroz irrigado. Habían desarrollado y estaban practicando una cultura del arroz irrigado tan desarrollada como la que se encuentra en Asia en ese periodo.
Según se desarrollaba el comercio de seres humanos, los informes de los marineros revelan la conciencia europea de los grupos étnicos que formaron las sociedades de arroz mangle en la costa norte de Guinea. El sistema baga fue esbozado y descrito para la posteridad por Samuel Gamble, que esclavizó la costa guineana de Conakry en 1793 (figura 2):

Figura 2

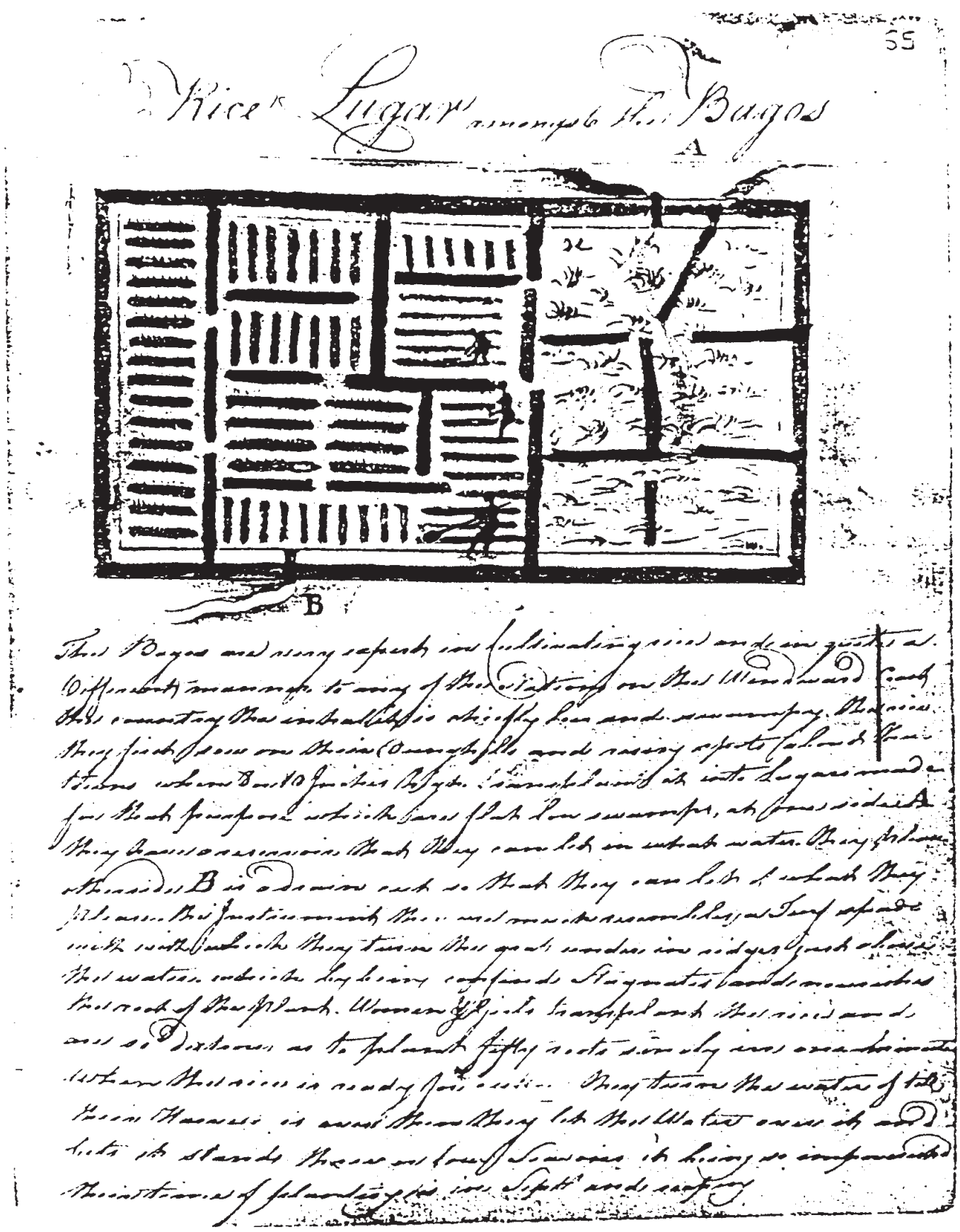


Los Bagos son unos expertos en cultivar el arroz y de una manera muy diferente a cualquiera de las naciones de la costa a barlovento [Sierra Leona]. El país que habitan es mayoritariamente de marga y pantanoso. Sembraron primero el arroz en los estercoleros y elevaciones de sus pueblos; cuando llega a 8 o 10 pulgadas, lo trasplantan a "Lugars" [campos] hechos para ese propósito que son pantanos bajos y llanos, en un lado... tienen una reserva que pueden llenar con el agua que quieran, [por otro lado]...hay un desagüe para que puedan sacar la que quieran (Littlefield 1981, pp. 93-95).

La comparación de Gamble del arroz de mangle con otros sistemas plantados en Sierra Leona también revela una concienciación europea de que el arroz que buscaban para la compra se cultivaba en diferentes ambientes, con frecuencia en una pendiente del paisaje. Esto era evidente ya en un periodo mucho más temprano en los comentarios del geógrafo de Ámsterdam, Olfert Dapper. Basándose en información dada por los mercaderes holandeses que operaban en la costa a barlovento en la región entre Sierra Leona y Liberia, cerca de 1640, Dapper ofreció información clara sobre los tres sistemas de arroz africanos. Su informe se enfocaba en el modelo de plantación de arroz en una pendiente del paisaje en la que el agua del río sobrante se convirtió en el cultivo de arroz para pantanos internos y elevaciones humedecidas por la lluvia:

Los que son trabajadores pueden cultivar tres campos de arroz en un verano; sembraron el arroz primero en un terreno bajo, por segunda vez en un terreno más alto y por tercera...en tierra alta, una vez al mes después de la anterior, para no tener todo el arroz maduro al mismo tiempo. Eso les hubiera dado dificultades para cortar el arroz por cortarse mazorca a mazorca o caña a caña-una labor agotadora. Esta es la práctica más común en todo el país. El primer arroz o arroz temprano, sembrado en zonas bajas y húmedas... el segundo, sembrado en una tierra un poco más alta...el tercero, sembrado en tierra alta... (Richards, 1996, pp. 209-229).

Los comentarios de Dapper del siglo diecisiete revelan un entendimiento abarcador de los medios agrícolas más importantes en el África Occidental. Los comentarios tempranos europeos sobre el arroz, hechos desde el barco o en breves estadías en tierra, describen usualmente sólo la porción baja de la pendiente del arroz, la sección que podían ver los marineros fácilmente como los humedales o los sistemas de arroz mangle. Pero según los europeos establecieron fuertes y centros comerciales a lo largo de la costa norte de Guinea durante el siglo diecisiete, entraron en contacto con otros sistemas de producción que usaban los excedentes de arroz para la venta.

Otras características de la cultura de arroz del África Occidental que atrajeron la atención incluyeron el sistema del uso de tierra agrícola/pastoral y la organización social de la producción del cultivo. El comerciante de esclavos Francis Moore, que trabajó en el río de Gambia durante la tercera década del siglo dieciocho como un distribuidor para una compañía inglesa, dio cuenta del cambio estacional en el uso de la tierra entre granjeros y pastores en los humedales del río, apuntando que la tierra del arroz durante la estación seca se convertía en pasto de ganado (Moore, 1738). Después de la cosecha, el ganado pastaba el rastrojo y su movimiento incrementaba la fertilidad del terreno, que volvía a cultivarse con arroz durante la época de lluvias.

Desde un periodo temprano, las crónicas europeas mencionan los aspectos relativos al género de la cultura de arroz del África Occidental, especialmente el papel de las mujeres en el cultivo del arroz y su procesamiento. Al hablar sobre las compras de comida de los negociantes holandeses en el Cabo Mount, cerca de la frontera de Liberia con Sierra Leona en 1624, Samuel Brun escribió "por el arroz sólo querían corales de vidrio para sus esposas, porque el arroz es un bien de las mujeres" (Brooks, 1993). En la misma década en el río de Gambia, Richard Jobson ofreció una descripción detallada del papel de la mujer en procesamiento del arroz: "Estoy seguro de que no otra mujer puede hacer tal servidumbre: con unos palos grandes que llamamos morteros, golpean y limpian el arroz y todos los otros cereales que comen. Es trabajo de mujeres y muy penoso" (Jobson, 1904 (1623), p. 68). Al escribir sobre Sierra Leona en 1680, el comerciante de esclavos Jean Barbot observó: "La tierra abunda en mijo o maíz blanco [sorgo] y en arroz que es su comida principal. Las mujeres golpean el arroz en troncos de árboles que tienen pequeños agujeros" (Hair, Jones y Law, 1992, p. 186). Medio siglo más tarde, Francis Moore observó que el arroz era únicamente un cultivo de mujer: "Todos los pueblos tienen dos campos comunes de tierra despejada: uno para su maíz [inclusive mijo y sorgo] y el otro para el arroz...Los hombres trabajan el terreno del maíz y las mujeres y las niñas, el del arroz" (Moore, 1738, p. 127). El cultivo del arroz mangle, sin embargo, con frecuencia requería una división de labor basada en el género, los hombres se concentraban en limpiar el terreno y las mujeres eran responsables de usar la azada, quitar las malas hierbas y trasplantar el cereal (Golberry, 1803). 
Estas crónicas revelan que el cultivo del arroz estuvo generalizado en la costa norte guineana cuando llegaron los portugueses a mediados del siglo quince. Los portugueses no introdujeron el cultivo del arroz ahí, a partir de sus viajes a Asia, como defenderían historiadores más tarde, sin ningún sentido crítico. Las tres formas principales del cultivo de arroz en África Occidental (el que depende de la lluvia, el pantano en tierra adentro y el terreno inundable por las mareas) antecedieron a su llegada.

\section{LA ANTIGÜEDAD DEL DESARROLLO DEL ARROZ AFRICANO}

Fue en el delta del Río Negro en Mali donde los hablantes de las lenguas Mande hicieron una contribución significativa a la prehistoria africana al cultivar el arroz africano (Oryza glaberrima). Sólo en el siglo veinte se desarrolló y probó esta hipótesis. Las crónicas tempranas portuguesas que mostraban que el cultivo del arroz estaba ya establecido en la costa del África Occidental cuando llegaron en el siglo quince se había borrado de la memoria durante cuatro siglos de esclavitud atlántica. Al comienzo del colonialismo europeo desde el final del siglo diecinueve, los académicos atribuían, rutinariamente, la presencia del arroz en África Occidental a la introducción del arroz procedente de Asia por los portugueses (Ribiero, 1962). Estas perspectivas fueron reexaminadas cuando botánicos franceses, que trabajaban en el oeste de Sahel donde se originó glaberrima,_observaron características inusuales del cereal que sugerían que era de una especie diferente. El reexaminar las colecciones botánicas extraídas de la costa norte de Guinea durante el siglo diecinueve probó que esos especímenes de arroz también compartían el color rojo y unas características determinadas. Se estableció un consenso científico más amplio sobre el hecho de que el arroz glaberrima es una especie diferente, cultivado de manera independiente en África Occidental, para la segunda mitad del siglo veinte ${ }^{2}$.

Como consecuencia del tardío reconocimiento de que el arroz también era indígena de África Occidental, la investigación languideció en los esfuerzos para determinar el periodo de cultivo del arroz. Durante la década de los 70, el botánico francés Roland Portères hizo el primer esfuerzo para datar la antigüedad de la cultivación del arroz africano. Basándose en la datación por radiocarbono de los asentamientos megalíticos localizados en humedales dejados por cursos de ríos antes existentes, atribuyó el cultivo de glaberrima a hace unos 3500 años (Portères, 1976, pp. 409-452).
La investigación arqueológica reciente de Susan Mclntosh establece la presencia del cultivo de glaberrima entre 300 antes de Cristo y 300 después de Cristo en el delta interno del río Niger en Mali (Mclntosh, 1995). No se ha conducido ninguna otra investigación arqueológica todavía en la región del arroz del África Occidental, que se extiende de Senegal a Liberia y tierra adentro más de mil millas al Lago Chad en el país moderno con ese nombre (figura 3). El desarrollo de la producción de hierro en la región durante el primer milenio después de Cristo sin duda contribuyó a la difusión del arroz africano en un área vasta de África Occidental. Artículos agrícolas duraderos, hechos de hierro, facilitaron el despeje del bosque, permitiendo así la difusión del arroz a bosques de hoja caduca en zonas montañosas y a estuarios costales de mangle, localizados al sur y suroeste del Río Negro.

\section{LA HISTORIA DEL ARROZ EN CAROLINA DEL SUR}

En ningún otro lugar de las Américas fue tan importante el papel económico del arroz como en Carolina del Sur. Según el testimonio de John Stewart uno de los primeros colonos, el cultivo del arroz por los esclavos para su subsistencia había comenzado en la primera década de asentamiento de la colonia de Carolina en 1670 (Wood, 1974, pp. 57-58). Para la década de los 90 , el cereal ya se cultivaba para su exportación. En la víspera de la Revolución americana, las exportaciones anuales de Carolina del Sur excedían los sesentaiséis millones, haciendo del arroz el primer cereal que se comercializó globalmente.

Unos cien esclavos africanos acompañaron a los primeros europeos que llegaron a Carolina del Sur desde Barbados en 1670. En dos años, los esclavos formaron una cuarta parte de la población de la colonia; para 1708 , la población negra excedía el número de la blanca (Wood, 1974, pp. 25-26, 36, 143-145). Desde ese periodo en adelante, Carolina del Sur se convirtió en una colonia con mayoría negra. Mientras que los esclavos cultivaban el arroz de la colonia y las exportaciones de índigo, también cultivaban los cereales para la subsistencia y eran consumidos por los dos, blancos y negros. Siguiendo un modelo similar al de las Islas de Cabo Verde, los esclavos de la región de arroz del África Occidental plantaban su alimento de primera necesidad favorito durante el periodo más temprano del asentamiento en Carolina del Sur.

Las crónicas históricas indican múltiples introducciones de la semilla del arroz entre 1685 y el principio de la década de 1690, unas deliberadas y otras casuales. Dentro de los tipos de semilla cultivados tempra- 


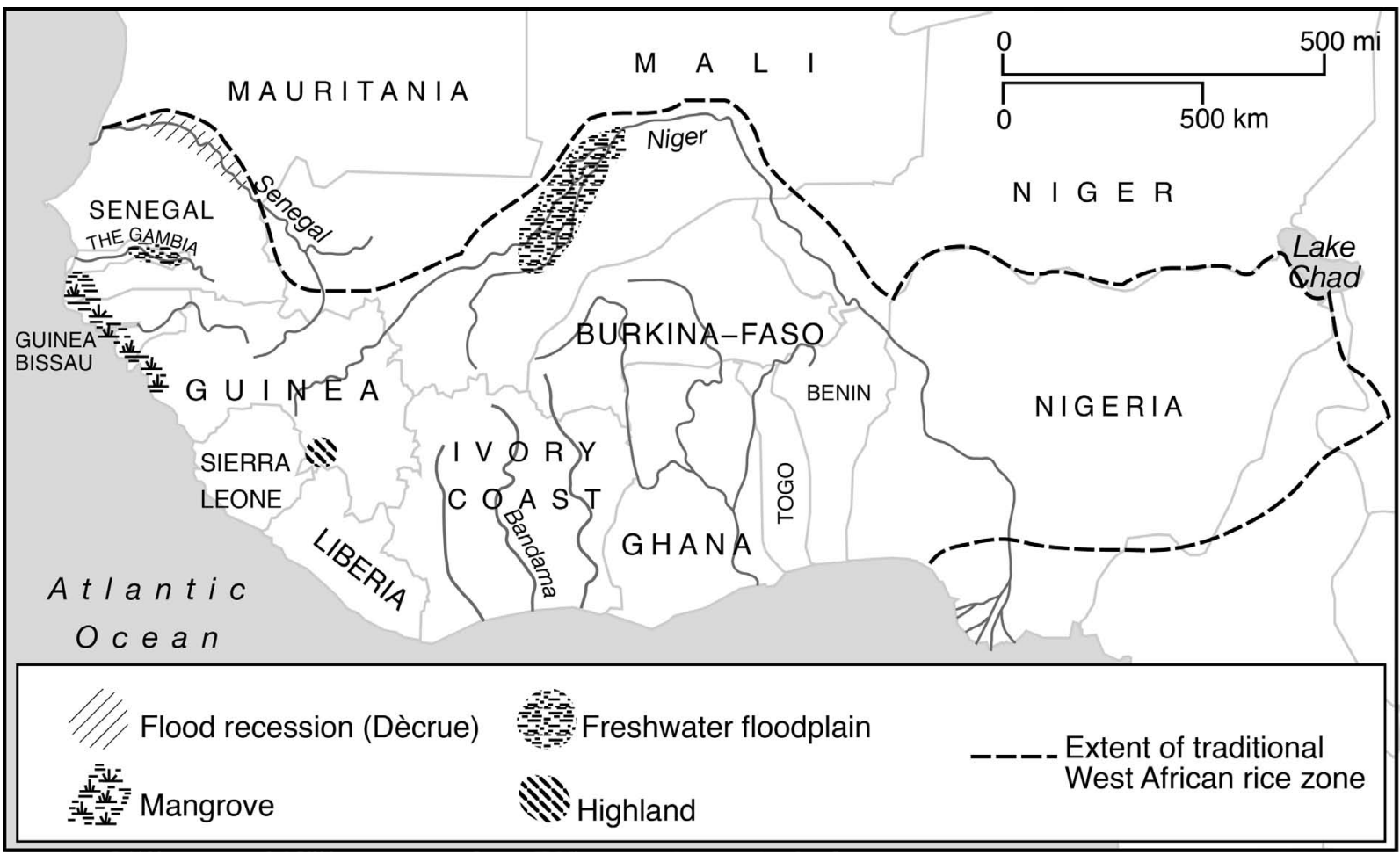

namente en Carolina del Sur había uno de color rojo: "uno llamado Arroz Rojo, en contraposición al blanco, del rojo de su cáscara o piel [salvado] aunque los dos se limpian y se ponen blancos" (Salley, 1919, p. 11). El color rojo diferencia el glaberrima del arroz asiático sativa ${ }^{3}$. Es bastante probable que el arroz africano entrara a la colonia en barcos de esclavos en el periodo de asentamiento temprano de Carolina del Sur. Al escribir al principio del siglo veinte, cuando los académicos creían que el arroz se originaba únicamente en Asia, el historiador del sur A.S. Salley relacionó los tipos de arroz cultivados más tempranamente con los capitanes de barcos que llevaban la semilla a la colonia de sus viajes a Asia. Sobre lo que llevaban los barcos durante la mitad de su trayecto alrededor del mundo a Carolina del Sur, el tipo de cargamento que llevaban y dónde paraban en el viaje desde Asia, su comentario guarda silencio. La aparición del cereal se presenta simplemente como intercambios deliberados de semilla entre caballeros bien viajados.

Una crónica que sobrevive del periodo de asentamiento temprano sugiere, incluso, otro mecanismo para la introducción del arroz a la colonia, uno que probablemente estableció el glaberrima. El arroz entró a la colonia como una provisión sobrante en los barcos de esclavos: un barco Portugués llegó, con esclavos del este, con una cantidad de arroz considerable, al ser la provisión del barco: este arroz lo tomaron alegremente los Carolinos a cambio de un suministro de su propio producto. Este cargamento inesperado fue distribuido, lo que renovó el espíritu de la empresa, pero no fue suficiente para suministrar la demanda de aquellos que hubieran querido plantarlo (Collinson, 1766, pp. 278-280).

La mención de la abundancia de arroz como la provisión del barco de esclavos hace poco probable que su fuente fuera otra que África Occidental. Este arroz era definitivamente el glaberrima y probablemente la fuente del tipo rojo de arroz mencionado entre esos que se cultivaban en la década de 1690 . El arroz africano figuraba entre los tipos cultivados más tempranamente y probablemente liderara, bajo el cuidado de los esclavos, el establecimiento de cereal en la colonia, primero para la subsistencia y después para el comercio.

El arroz llevado a bordo de los barcos de esclavos sirvió como semilla, pues parece haber sido comprado por esclavos en la costa africana occidental como arrozal (con cáscaras incluidas). La evidencia de archivos disponible, aunque escasa, sugiere que el cereal fue entonces molido para su consumición por las esclavas africanas. En una entrada de un diario a bordo del barco de esclavos Mary, que salía de Senegal y está 
fechado el lunes, 10 de junio de 1796 se lee: "los hombres [la tripulación] empleaba esclavos y personas diversas para las tareas necesarias en el barco... las mujeres limpiaban arroz y molían maíz para los pasteles de maíz" (Donnan, 1930-1935 (1932), pp. 121, 376). Los barcos de esclavos aparentemente dependían de las habilidades de procesamiento de las mujeres esclavas para moler el arroz y preparar comidas a través del comercio triangular. Henry Smeathman, un observador del negocio de esclavos en Sierra Leona al comienzo de la década de 1770, ofrece una historia desgarradora sobre el papel de las mujeres esclavas al moler el arroz a bordo de los barcos de esclavos:

¡Ay! Qué escena de miseria y angustia es un barco cargado de esclavos cuando llueve. El rechinar de las cadenas, los quejidos de los enfermos y el hedor de todos es casi insoportable...se tiran a dos o tres esclavos por la borda un día sí y otro no cuando mueren de fiebre, flujo, sarampión, todos juntos como gusanos. Todo el día rechinan las cadenas o el sonido del armero que sujeta con remaches a un pobre diablo que acaba de llegar a los grilletes pesados y mortificantes. Las mujeres esclavas en una parte del barco golpean el arroz con morteros para limpiarlo y cocinarlo ${ }^{4}$.

Mientras que los esclavos de Carolina continuaron plantando "arroz de Guinea" en sus jardines para la comida hasta principios del siglo diecinueve, la economía de exportación de Carolina se había cambiado hacía mucho tiempo al arroz asiático (Drayton, (1802) 1972, p. 125). El arroz sativa es más rentable que el arroz africano pero, de manera significativa, no se rompe tan fácilmente como el glaberrima con la fresadora mecánica. Sólo el procesarlo a mano con un mortero, como lo han hecho siempre las mujeres africanas, minimiza el problema de romper el glaberrima. La emergencia del cereal como un cereal de exportación dependió de aprender cómo manejar a mano el arroz con el mortero, una habilidad que introdujeron las mujeres esclavas. La introducción de los aparatos mecánicos de mediados del siglo dieciocho para mejorar la productividad del trabajo de esclavos aseguró el dominio del arroz asiático en los mercados de exportación.

\section{LA TRANSFERENCIA DE LA TECNOLOGÍA AFRICANA A LA CULTURA DEL ARROZ DE CAROLINA}

Una evaluación de las crónicas de archivo y fuentes secundarias revela los numerosos antecedentes africanos a la producción de arroz en Carolina. Hay una correspondencia asombrosa entre sistemas de trabajo de la tierra. Una forma de cultivo, procesamiento y métodos de cocina idéntica emergieron en la colo- nia, basados en instrumentos y artilugios de la cultura del arroz. Incluso el sistema de trabajo que apareció en las plantaciones de Carolina, como se discute en la próxima sección, sugiere la agencia africana en el desarrollo del cultivo. A pesar de la naturaleza fragmentaria de la historia temprana sobre el arroz en la colonia de Carolina, los tres tipos de sistemas de arroz son evidentes para 1730.

El cultivo inicial del arroz como cereal de subsistencia se planteó como complemento con la crianza de ganado. El arroz alimentado por la lluvia, que crecía en boques despejados, fue común al principio del siglo dieciocho. Los esclavos talaban pinos para leña y extraían el alquitrán, el betún y la resina que se vendían para sellar los barcos (Otto, 1989). La carne de res también se convirtió en mercancía para la exportación como carne salada para los viajes transoceánicos en la época de navegación. Siguiendo el modelo africano, el sistema de arroz alimentado por la lluvia se desarrolló como parte de un uso de tierra rotacional para el ganado. (Nairne, 1710, pp. 33-73). Algunos de los esclavos que llegaron a Carolina del Sur sin duda poseían un conocimiento de ambas cosas, el cultivo de arroz y la crianza de ganado, puesto que los rebaños estaban muy difundidos por la costa norte de Guinea y se ha planteado a Carolina del Sur como una fuente posible de la tradición de los ranchos de Norteamérica.

El aumento dramático de esclavos en las primeras décadas del siglo dieciocho-de tres mil en 1703 a veintinueve mil en 1739-proporcionó a los propietarios de la plantación la fuerza de trabajo suficiente para limpiar pantanos y desarrollar una economía floreciente al cultivo de arroz en pantanos en tierra adentro de alto rendimiento (Wood, 1974, pp. 143145). El cultivo de arroz en los pantanos interiores involucraba incautar agua de la lluvia para la saturación del suelo conjuntamente con fuentes derivadas de manantiales subterráneos, capas freáticas o riachuelos. Este sistema de arroz proporcionaba control sobre las inundaciones y un drenaje en épocas críticas del ciclo de cultivo. El objetivo era inundar la maleza y reducir el trabajo de limpieza (Heyward, 1937). Una lógica y sistema idéntico caracterizaban el cultivo del arroz en los pantanos de tierra adentro.

Una de las referencias más tempranas al significativo cambio en el uso de la tierra en la producción del arroz de Carolina apareció en 1738. Un documento sobre la venta de una tierra por William Swinton de Winyah Bay, en Carolina del Sur revela el énfasis cada vez mayor en el arroz cultivado por las mareas: "cada uno [de los campos] contiene tanto caudal, que daría 
para dos campos y 20 negros, se llena de agua dulce con cada marea y, por lo tanto, no está sujeta a sequías" ${ }^{\prime 2}$. Este cambio a las orillas inundables de los ríos (conocido como el arroz de las mareas) permaneció como la base para la bonanza económica de la región hasta la desaparición del cultivo de arroz después de la Guerra Civil. Aunque la creación de una plantación por mareas requería enormes cantidades de trabajo, una vez puesta en marcha el tiempo que se pasaba en quitar las malas hierbas se redujo, en comparación a antes, debido a la inundación controlada del río. John Gerard William de Brahm, inspector de la colonia a mediados del siglo XVIII, reportaba que un esclavo era, entonces, capaz de encargarse de cinco acres de terreno, en lugar de los dos acres que típicamente se plantaban en el cultivo de arroz tierra adentro (Brahm, 1971, pp. 61-131).

Los propietarios de las plantaciones sabían que muchos de sus esclavos habían cultivado arroz, antes de convertirse en esclavos; eran conscientes, también, de qué grupos étnicos africanos se especializaban en su cultivo. Este conocimiento provenía de su contacto sostenido con los esclavos al dar forma a la frontera de Carolina y su dependencia en cultivar alimentos de primera necesidad para su supervivencia mutua. Los anuncios de periódico revelan esta conciencia, al anunciar ventas inminentes de esclavos que estaban familiarizados con la cultura del arroz. Un periódico de Charleston anuncia la venta de 250 esclavos "de la costa de arroz y de a barlovento, valorados por su conocimiento de la cultura del arroz". Otro del 11 de julio de 1785 anunció la llegada de un barco danés con "una elección de cargamento de negros de las costas de a barlovento y la costa dorada, que han estado acostumbrados a plantar arroz" (Clifton, 1981, pp. 273; Wood, 1974b, pp. 170-171). Semejante conocimiento sobre los esclavos arroja luz sobre la clara preferencia de los propietarios de plantaciones de Carolina por esclavos de Gambia y la costa a barlovento (Sierra Leona) - dos zonas de arroz significativas de la costa norte de Guinea durante el periodo crucial del desarrollo del arroz cultivado en base a mareas en el siglo dieciocho.

Como su prototipo (el sistema de arroz mangle), un propietario de plantación de Carolina observó que la plantación de marea era una 'enorme máquina hidráulica' que dependía de un "aparato de niveles, puertas, cajas, canales, paneles, zanjas que necesitan habilidad y coherencia para funcionar" (Doar, 1970, p. 8). Los esclavos de la zona del arroz del África Occidental que poseían este conocimiento de ingeniería se convirtieron en la fuerza de trabajo preferida para transformar los humedales de los pantanos en campos de arroz productivos.

La preparación de un humedal para el cultivo de arroz seguía principios significativamente parecidos a aquellos del sistema del arroz mangle. Primero, los esclavos construían diques alrededor de terrenos en forma rectangular de las marismas. El campo de arroz estaba lo suficientemente protegido para prevenir que cayera encima el agua de la marea. La tierra que se quitaba en el proceso resultaba en un canal adjunto, mientras que las compuertas que se construían en los diques operaban como válvulas para las inundaciones y el drenaje. Cuando se abría en marea alta, el agua entraba para inundar el campo. Al cerrarse en marea baja, el agua quedaba en la cosecha. Al abrirlo otra vez en marea menguante, el exceso de agua salía de la tierra. El agua del río entraba en diques secundarios. El sistema funcionaba exactamente igual que el arroz mangle en África.

En las plantaciones de Carolina, a las compuertas de les llamaban "trunks", por haber dependido las colonias, al principio, del método africano para hacer circular agua en el perímetro del arroz. Se construían a partir de troncos de árbol huecos con un tapón que se ponía en un extremo antes de ser reemplazados por puertas que colgaban en vertical en el periodo colonial (Hilliard, 1978). Este es exactamente el sistema de control de agua que todavía se usaba en la producción de arroz mangle en África Occidental.

Otros artefactos también arrojan luz sobre los antecedentes africanos. La azada es el artículo agrícola primario usado a través de toda la zona de arroz del África Occidental. Indispensables para el trabajo de las mujeres en la cultura de arroz africana, hay dos versiones, una larga usada para la preparación del campo y otra corta para el trabajo más minucioso y para desherbar. Grabados y pinturas diferentes sobre las plantaciones de arroz americanas del periodo colonial representan esclavos, generalmente mujeres esclavas, que llevan o están trabajando con la azada larga. Las crónicas escritas sobre la cultura del arroz de Carolina mencionan también el uso de azadas cortas, de cuatro y ocho pulgadas de longitud, para el trabajo minucioso de los terrenos (Lewis, 1958).

Otras tres técnicas de las plantaciones de Carolina también revelan los antecedentes africanos. Las mujeres sembraban arroz por toda el África Occidental. Esto también era trabajo de las mujeres esclavas. El sembrado también incluía echar semillas a la tierra en 
las zanjas y usar el pie para cubrirla. Un origen africano es también evidente en un segundo, aunque menos común, método de sembrado, que conllevaba cubrir las semillas en arcilla antes de plantarlas. La técnica es similar a la que se practicó durante mucho tiempo en África Occidental, donde las mujeres envolvían las semillas en estiércol de ganado y/o barro para protegerlas contra pájaros, insectos y parásitos microbianos. Una tercera práctica de cultivo africana se adoptó en las plantaciones de Carolina. Esta práctica consistía, según un plantador, en que el arroz se sembrara directamente en el agua dulce de los humedales, en lugar de trasplantarlo (Allston, 1846, pp. 320-327).

Otro grupo de técnicas que subrayan la importancia de la pericia en la materia de las mujeres esclavas en la historia del arroz de Carolina es la manera de moler y cocinar el arroz. Durante la mayor parte del periodo colonial, el arroz fue molido en un mortero de madera a mano y aventado en cestas que se llevaban en la mano. Hasta la llegada de los artefactos mecánicos conducidos por el agua, durante la segunda mitad del siglo dieciocho, el molido del arroz se hacía de la forma africana con un mortero de madera, a mano y de manera vertical, de la misma manera que las mujeres han procesado la comida de manera tradicional en todo el continente africano. El procesamiento del arroz también conlleva el desquite de las cascarillas que no se pueden ser digeridas, un proceso conocido como aventar. En la región africana del arroz, el aventar implica poner el arroz que ha sido molido a mano, una mezcla de granos y cascarillas vacías, en cestas circulares y poco profundas. Los granos y las cascarillas se rotan dentro y se tiran al aire, lo que deja los granos con la cascarilla más pesada dentro de la cesta. La economía del arroz del Sur de Carolina seguía este mismo método.

Incluso el mismo estilo de tejer las cestas usadas para aventar mostraba un origen africano, como ha establecido Dale Rosengarten. En un análisis comparado de las tradiciones de tejer cestas africano y nativo americano, Rosengarten enlaza las cestas hechas para aventar con una tradición derivada del África Occidental. Las cestas de los indios del sureste empleaban un diseño hecho de trenzas o sargas, que tienen unos orígenes diferentes. Las cestas para aventar, en contraste, tenían formas de bucle. A través de un análisis de los estilos de tejido en las colecciones de cestas en museos de Europa y Norte América, Rosengarten localiza el prototipo de la cesta para aventar en la región de Senegambia en África, que aparecía en múltiples comentarios europeos sobre la cultura del arroz desde el siglo dieciséis (Rosengarten, 1997).
Los métodos para cocinar el arroz revelan asociaciones adicionales con África. La cocina de plantación de Carolina prefería la separación entre los cereales, de la manera en que los platos de arroz africanos se cocinan típicamente. Los platos de arroz de manera similar se cocinaban con habichuelas (el plato de "hoppin' John", basado en frijoles de ojos negros, una planta africana) y con frecuencia añadían ocra, otra planta nativa de África. Las mujeres africanas también desarrollaron un método de cocina del arroz de cocerlo a medias, otro nombre para el arroz "converted", que hoy en día se vende bajo el nombre de "Uncle Ben's Converted Rice".

Esta evaluación de los métodos, artefactos y prácticas de cultivo y proceso revela la transferencia de un sistema entero de la cultura de arroz del África Occidental a la colonia del Carolina del Sur desde el final del siglo diecisiete. A través de grupos étnicos especializados en el cultivo del arroz y el conocimiento especializado de las mujeres, el arroz se enraizó en el borde occidental del océano Atlántico. La importancia del conocimiento del arroz y su difusión de acuerdo al sexo es un recordatorio riguroso de cómo la esclavitud desmontó un sistema de cultivo africano para servir las necesidades de la economía de exportación de plantación. En los sistemas africanos, el cultivo del arroz en medios agrícolas diversos aseguró la subsistencia y redujo el atascamiento de las labores de trabajo. La historia del arroz de Carolina revela cómo el uso de la tierra cambió como respuesta a la demanda del mercado de exportación y la disponibilidad del trabajo de los esclavos. Aunque estaba basado en sistemas de conocimiento de las mujeres, un análisis de la cultura del arroz de Carolina muestra que la división del trabajo basada en género, característica de la producción en África, también cambió con la esclavitud, según se enseñaba a los chicos el cultivo y las técnicas que tradicionalmente habían aprendido las chicas. Algo más que el cultivo del arroz se enraizó en las Américas: un sistema de conocimiento indígena africano que se aplicaba tanto a los campos como a la cocina estableció el cultivo del arroz en las Américas y el cereal que pervive como fundamental para la identidad cultural entre los descendientes de los esclavos que plantaban arroz.

\section{LAS PLANTACIONES DE ARROZ Y LA DIVISIÓN DEL TRABAJO}

Al intentar establecer los alimentos de primera necesidad favoritos en los pantanos que lo permitían, los esclavos enseñaron a los propietarios de las plantaciones cómo cultivar y moler arroz y cómo poner en práctica el complicado sistema de 
control del agua que representó una transformación masiva del paisaje. Pero al asignar agencia a los esclavos, queda una duda fundamental. ¿Por qué transferirían los esclavos un sistema de conocimiento de un cereal cuyo cultivo les haría permanecer cinco meses al año en pantanos de malaria y les obligaría a trabajar un número de horas infinitas esforzándose a moler con la mano el cereal para su exportación? La respuesta probablemente tenga que ver con el sistema de trabajo que caracterizaba las plantaciones de arroz.

Un sistema de trabajo poco usual, que no era característico de otros sistemas de plantación americanos, surgió en las zonas de cultivo de arroz de Carolina del Sur y Georgia. Se le conoció como el trabajo por "tareas" para distinguirlo del otro sistema más extendido en la esclavitud, el trabajo por "bandas". En el trabajo por bandas, los esclavos eran forzados a trabajar del amanecer al anochecer. El sistema de tareas en las plantaciones de arroz sin embargo, asignaba a cada esclavo una tarea en los campos de arroz. Sin desestimar todas las exigencias de trabajo del sistema de labores, para los robustos físicamente, sanos y jóvenes, el sistema de labores significaba que, cuando acababan su tarea, el tiempo que quedaba en el día le pertenecía al esclavo. El completar la tarea significaba tener la oportunidad para dedicar una porción de cada día a actividades que mejoraban la comida de subsistencia como plantar en los jardines traseros, pescar y poner trampas. Al contribuir a la nutrición de todos, estas actividades podían mejorar la subsistencia, nutrición y supervivencia de los esclavos de manera crucial. Está documentado que la división del sistema de trabajo por tareas existía ya desde 1730 en Carolina del Sur, tempranamente en el periodo colonial y en un momento en que se estaba desarrollando el trabajo para crear las plantaciones por marea (Morgan, 1972, pp. 563-599).

La aparición, entonces, de un sistema de trabajo diferente que no era el típico de la plantación de los esclavos en las Américas en las plantaciones de arroz del Sur de Carolina en el periodo colonial temprano añade evidencia indirecta del importante papel africano en el desarrollo del cultivo del arroz ahí. El conocimiento del cultivo del arroz, un sistema agrícola indígena de África Occidental, conocido de algunos de los esclavos del sur de Carolina, proporcionó a los esclavos la habilidad de negociar los términos de su cautiverio. En este sentido, entonces, el sistema de trabajo por tareas puede ser visto como lo que permitió a los esclavos una resistencia parcial a las demandas diarias de su esclavitud durante el periodo colonial, cuando las relaciones de trabajo entre los esclavos y los que les esclavizaban no se habían consolidado todavía. La frontera quedaba abierta todavía y la posibilidad de escapar como esclavo fugitivo o escapar a las comunidades de los nativos era todavía bastante real.

Sin embargo, según la esclavitud se consolidó después de la revolución americana y el cierre de fronteras bloqueó los caminos de escape a la Florida Española, la labor también se incrementó, lo que minó las ventajas conseguidas con la negociación de periodo colonial temprano. El trabajo por tareas, entonces, en las décadas finales de la esclavitud en los campos de arroz no era muy diferente del sistema de trabajos por grupos de otras plantaciones del Sur.

\section{CONCLUSIÓN}

Carolina del Sur y Georgia no son los únicos ejemplos documentados del cultivo por agua de marea fuera del África Occidental. El cereal también se plantó a mediados del siglo dieciocho en Maranhão, Brasil con esclavos importados directamente de la región del arroz de Guinea-Bissau (Correira, 1983). Aunque las plantaciones no pueden compararse con la producción de Carolina, el papel africano en la transferencia del cultivo del arroz al Nuevo Mundo se extendió más allá del sistema de exportaciones. Los esclavos en el Caribe francés cultivaron el arroz con frecuencia en jardines de subsistencia, que estaban plantados al lado de las plantaciones de café y arroz (Morrissey, 1989). En una fecha tan temprana como 1579, un becario español en Tabasco, Méjico escribió comentarios sobre el cultivo del arroz en una zona en la que había esclavos africanos para la producción del tabaco ("Relaciones de Yucatan", 1898: vol. 1, núm. 11). Los esclavos fugitivos de Surinam basaban la subsistencia de sus comunidades fugitivas cultivando arroz en pantanos en tierra adentro, establecidos fuera de la zona de plantación del azúcar- una región similar a las tierras bajas de la costa del golfo de Méjico que eran plantadas por los esclavos fugitivos (Price, 1992). Mediante la esclavitud y las comunidades de esclavos fugitivos, los africanos de occidente llevaron su cultura del cultivo del arroz a toda la América tropical.

La cultura del arroz representa un sistema de conocimiento indígena africano que acompañó a la esclavitud en las Américas, a las plantaciones de Carolina del Sur, como el cereal de provisión preferido en el sur de Estados Unidos, Brasil y Cuba; como alimento de primera necesidad para los esclavos fugitivos en las 
Guineas, Brasil, Méjico, Centroamérica y el Caribe. Y el arroz continúa como alimentos de primera necesidad en muchas de estas áreas hoy en día entre granjeros de descendencia africana mixta. El arroz forma, además, una parte crucial de mucha de la cultura culinaria asociada con la diáspora africana: El Hoppin' John de la cocina de Carolina, el "gumbo" de Luisiana, los moros y cristianos (arroces y habichuelas) de Cuba y el gallo pinto de Nicaragua. Central a la identidad cultural del Atlántico Negro, el arroz representa un legado importante de África Occidental en las Américas.

\section{NOTAS}

1 El trabajo de campo se realizó a partir de una estancia de investigación de quince meses desde 1983 hasta 1984, así como en viajes de investigación de tres o cuatro semanas efectuados entre 1987 y 1996.

2 El conocimiento botánico de un arroz africano nativo se traza en Judith A. Carney 2001. Black Rice. The African Origins of Rice Cultivation in the Americas. Cambridge, Mass., Harvard University Press.

3 Cabe señalar, sin embargo, que mientras que las cascaras del arroz glaberrima son siempre de color negro rojizo, algunas variedades de arroz sativa también comparten este rasgo.

\section{BIBLIOGRAFÍA}

Allston, R.F.W. (1846), "Memoir of the Introduction and Planting of Rice in South Carolina", De Bow's Review, 1, pp. 320-357.

Barry, Boubacar (1998), Senegambia and the Atlantic Slave Trade. Cambridge, University Press.

Blake, J.W. (1977), West Africa: Quest for God and Gold, 1545-1578. London, Curzon Press.

Brooks, George (1993), Landlords and Strangers. Ecology, Society and Trade in Western Africa, 1000-1630. Boulder, Westview Press.

Brahm, John Gerard William de (1971), "De Brahm's Report". En: Vorsey, Jr., Louis de (ed.) Report on the General Survey in the Southern District of North America, Columbia, University of South Carolina Press, pp. 61-131.

Carney, Judith (2001), Black Rice. The African Origins of Rice Cultivation in the Americas. Cambridge, Mass, Harvard University Press.

Carreira, A. (1984), Os portuguêses nos rios de Guiné, 1500-1900. Lisbon, privately published.

Clifton, James (1981), "The Rice Industry in Colonial America", Agricultural History, 55, pp. 266-83.

Collinson, P. (1766), "Of the Introduction of Rice and Tar in our Colonies", Gentleman's Magazine, 36 June, pp. 278-280.

Crone, G. (1937), The Voyages of Cadamosto. London, Hakluyt.
Su historia en el Atlántico occidental revela que las plantas africanas tuvieron un lugar prominente como provisiones en los barcos de esclavos, así como en intercambios informales de semillas que permitió a los esclavos establecerlas como forma de subsistencia. Representa una manera loable de transferencia de tecnología, bajo condiciones de trabajo forzado difíciles de imaginar. En la historia compartida de esclavitud, comenzó la diáspora africana. Pero la diáspora africana fue una de plantas y de personas, cuya historia sólo hemos comenzado a explorar.

4 Henry Smeathman a Drury, Sierra Leona, 10 de Julio de 1773. MS D.26 Universidad de Uppsala. Agradezco la cita a Starr Douglas, estudiante de doctorado en Royal Holloway, Universidad de Londres.

5 Anuncios para la venta de tierra fechados el 19 de enero de 1738 publicados en la South Carolina Gazette, Charleston, 1738.

Curtin, Philip (1975), Economic Change in Pre-Colonial Africa. Madison, University of Wisconsin.

Davies, K.G. (1970), The Royal African Company. New York, Atheneum.

Doar, David (1970 [1936]), Rice and Rice Planting in the South Carolina Low Country. Charleston Museum, Charleston, S.C.

Donnan, Elizabeth (1930-1935), Documents Illustrative of the History of the Slave Trade to America. (4 vols.), vol. 3. Washington, D.C., Carnegie Institution.

Drayton, John (1972 [1802]), A View of South Carolina. Columbia, University of South Carolina Press.

Duncan, T.B. (1972), Atlantic Islands: Madeira, the Azores, and the Cape Verdes in Seventeenth Century Commerce and Navigation. Chicago, Illinois, University Press.

Eanes de Azurara, Gomes (1899), The Chronicle of the Discovery and Conquest of Guinea, vol. 2, vol. 2. London, Hakluyt.

Fernandes, Valentim (1951 [c. 1506-1510]), Description de la Côte Occidentale d'Afrique. Bissau, Guinea Bissau, Centro de Estudos da Guiné Portuguêsa.

Golberry, S.M.X. (1803), Travels in Africa, performed during the years 1785, 1786 and 1787, in the Western Countries of this Continent, 2 vols. London, R. Bent, and J. Mudie. 
Gomes, Diogo (1959 [c. 1456]), En: Monod, Th., Mauny, R. y Duval, G. (eds.), De la Première Découverte de la Guinée. Récit par Diogo Gomes (Fin XV siècle), Bissau, Guinea-Bissau; Centro de Estudos da Guiné Portuguesa.

Lewis Gray (1958), History of Agriculture in the Southern United States to 1860, 2 vols. Gloucester, Mass, Peter Smith.

Hair, P.E.H.; Adam Jones, y Robin Law (eds.) (1992), Barbot on Guinea. The Wrirings of Jean Barbot on West Africa 1678-1712. London, The Hakluyt Society.

Heyward, Duncan (1937), Seed from Madagascar. Chapel Hill, University of North Carolina Press.

Hilliard, Sam B. (1978), "Antebellum Tidewater Rice Culture in South Carolina and Georgia". En: James Gibson (ed.), European Settlement and Development in North America: Essays on Geographical Change in Honour and Memory of Andrew Hill Clark, Toronto, University Press.

Jobson, Richard (1904 [1623]), The Golden Trade. Devonshire, Speight and Walpole.

Littlefield, Daniel C. (1981), Rice and Slaves. Baton Rouge: Louisiana State University.

McIntosh, Susan Keech (1995), Excavations at Jenne-jeno, Hambarketolo and Kaniana in the Inland Niger Delta (Mali). The 1981 Season.Berkeley, University of California Press.

Moore, Frances (1738), Travels into the Inland Parts of Africa. London, Edward Cave.

Morgan, Philip D. (1972), "Work and Culture: The Task System and the World of Low Country Blacks, 1700 to 1880 ". William and Mary Quarterly, $3^{\text {rd }}$ Series, 39, pp. 563-99.
Nairne, Thomas (1989) [1710], "A Letter from South Carolina". En: Greene, Jack P. (ed.), Selling a New World: Two Colonial South Carolina Promotional Pamphlets. Columbia, University of South Carolina Press, pp. 33-73.

Otto, John (1989), The Southern Frontiers, 1607-1860. New York, Greenwood Press.

Portères, Roland (1976), "African Cereals: Eleusine, Fonio, Black Fonio, Teff, Brachiaria, Paspalum, Pennisetum, and African Rice". En: Harlan, J., De Wet, J., y Stemler, A. (eds.), Origins of African Plant Domestication, Mouton, The Hague, pp. 409-452.

Relaciones de Yucatan (1898), Colección de Documentos Inéditos de Utramar, 2a serie, vol. 1, tomo num.11. Madrid, Impresores de la Real Casa.

Ribeiro, O. (1962), Aspectos e Problemas da Expansão Portuguésa. Lisbon, Estudos de Ciencias Políticas e Sociais, Junta de Investigações do Ultramar.

Richards, Paul (1996), "Culture and Community Values in the Selection and Maintenance of African Rice". En: Brush, S. y Stabinsky, D. (eds.) Valuing Local Knowledge. Indigenous People and Intellectual Property Rights, Washington, D.C., Island Press, pp. 209-29.

Rodney, Walter (1970), A History of the Upper Guinea Coast, 1545 to 1800. 1970. New York, Monthly Review Press.

Salley, A.S. (1919), "Introduction of Rice into South Carolina", Bulletin of the Historical Commission of South Carolina, 6. Columbia, South Carolina, The State Company.

Wood, Peter H. (1974), Black Majority. New York, Norton.

Wood, Peter H. (1974b), “'It was a Negro Taught them': A New Look at African Labor in Early South Carolina", Journal of Asian and African Studies, 9, pp. 160-179. 